\title{
UTILIZAÇÃO DE DIFERENTES TIPOS E CONCENTRAÇÕES DE CALDAS NUTRICIONAIS EM ATRIBUTOS AGRONÔMICOS DA ALFACE
}

\author{
Taísa Vargas* \\ Tânia Regina Pelizza** \\ André Luiz Radunz*** \\ Janaína Muniz ${ }^{* * *}$ \\ Daniele Casal ${ }^{* * * * *}$ \\ Siumar Pedro Tironi******
}

RESUMO: Objetivou-se avaliar o efeito da utilização de distintos tipos e concentrações de caldas nutricionais em atributos agronômicos da alface. O experimento foi conduzido em canteiros, em uma propriedade rural no município de Ronda Alta, (RS), de agosto a outubro de 2016. O delineamento experimental utilizado foi em blocos ao acaso, com sete tratamentos e cinco repetições. Os tratamentos utilizados foram: calda bordalesa a 0,1 e 0,5\%; húmus líquido a 2,5\% e 5\%; Microgeo ${ }^{\circledR}$ a $0,5 \%$ e $1,0 \%$; testemunha. As variáveis analisadas foram: altura da parte aérea, comprimento do sistema radicular, perímetro da parte aérea, matéria seca da parte aérea e do sistema radicular e redução de peso. Para a variável altura da parte aérea, o tratamento com calda bordalesa a $0,5 \%$ apresentou resultado superior ao tratamento com o uso de Microgeo ${ }^{\circledR}$ a $0,5 \%$. Para o comprimento da raiz o tratamento com húmus líquido a $5 \%$ igualou-se ao tratamento húmus líquido a 2,5\%, sendo aquele superior aos demais. Para a matéria seca do sistema radicular, o uso de húmus líquido e Microgeo ${ }^{\circledR}$, em ambas as concentrações, apresentaram os melhores resultados. Para a redução de peso da alface, a calda com húmus líquido e calda bordalesa a $0,5 \%$ apresentaram os melhores resultados. Assim, diante dos resultados obtidos com a condução deste trabalho, indica-se o uso de caldas nutricionais para o cultivo de alface. Sobre os atributos agronômicos, o uso de húmus líquido (2,5\% e 5\%) promove maior comprimento de raízes e menor redução do peso da alface.

\footnotetext{
*Engenheira agrônoma, Autônoma, Brasil.

** Doutora em Agronomia, Autônoma, Brasil. E-mail: trp_mestagro@hotmail.com

*** Doutor em Agronomia, Universidade Federal da Fronteira Sul - UFFS, Campus Chapecó, Brasil.

***** Doutora em Produção Vegetal, Instituto Federal de Santa Catarina - IFSC-Lages, Brasil.

${ }^{* * * * *}$ Graduanda em Agronomia, Universidade Federal da Fronteira Sul - UFFS, Campus Chapecó, Brasil.

${ }^{* * * * * *}$ Doutor em Fitotecnia, Universidade Federal da Fronteira Sul - UFFS, Campus Chapecó, Brasil.
} 
PALAVRAS-CHAVE: Biofertilizante; Calda bordalesa; Húmus líquido; Lactuca sativa; Microgeo $^{\circledR}$.

\section{USE OF DIFFERENT T YPES AND CONCENTRATIONS OF NUTRITIONAL BROTHS IN THE AGRONOMIC ATTRIBUTES OF LETTUCE}

ABSTRACT: The effect of different types and concentrations of nutritional broths in the agronomic attributes of the lettuce is evaluated. The experiment was conducted in vegetable beds on a farm in the municipality of Ronda Alta RS Brazil, between August and October 2016. Experimental design consisted of randomized blocks, with seven treatments and five replications. Treatments comprised Bordeaux broth at 0.1 and $0.5 \%$; liquid humus at $2.5 \%$ and $5 \%$; Microgeo ${ }^{\circledR}$ at $0.5 \%$ and $1.0 \%$; control. Variables analyzed were height of aerial segment, length of the root system, perimeter of the aerial segment, dry matter of the aerial segment and of the root segment, and weight decrease. Bordeaux broth at $0.5 \%$ for the variable height of aerial segment provided a greater rate than in the treatment with Microgeo ${ }^{\circledR}$ at $0.5 \%$. For root length, treatment with liquid humus at $5 \%$ was equivalent to humus treatment at $2.5 \%$, the former was superior to the others. In the case of dry matter of the root system, the employment of liquid humus and Microgeo ${ }^{\circledR}$, in the two concentrations, provided the best results. In the case of weight decrease, broth with liquid humus and Bordeaux broth at $0.5 \%$ provided the best result. Results indicate the use of nutritional broth for lettuce cultivation. Regard to agronomic attributes, the use of liquid humus (2.5\% and 5\%) provided the longest roots and the smallest decrease in lettuce weight.

KEY WORDS: Biofertilizer; Bordeaux broth; liquid humus; Lactuca sativa; Microgeo®.

\section{INTRODUÇÃO}

O cultivo de hortaliças tem se destacado no cenário do agronegócio em todas as regiões brasileiras, especialmente no Sul e Sudeste. Estimativas realizadas recentemente indicam que a safra brasileira de hortaliças ultrapassa 19 milhões de toneladas e movimenta mais de 24 milhões de reais para a economia do país (CLEMENTE, 2015).

Neste contexto, destaca-se a alface (Lactuca sativa L.), a qual é uma planta 
anual, originada de espécies silvestres, ainda atualmente encontradas em regiões de clima temperado, no Sul da Europa e na Ásia Ocidental. Pertence à família Asteraceae (Compostas), da qual fazem parte as hortaliças herbáceas de grande aceitação popular e mais consumidas na forma de saladas (FILGUEIRA, 2012).

Sabe-se, no entanto, do uso indiscriminado de agrotóxicos na agricultura. Deve-se considerar tal condição, já que se trata do fornecimento de produtos para o consumo humano. Nesse sentido, é necessário buscar alternativas viáveis de produção sem o uso de agrotóxicos, para que se possa produzir e consumir alimentos de qualidade. Assim, inerente a esta condição, uma prática benéfica aplicada nos sistemas de produção é a utilização de caldas nutricionais em substituição ao uso de produtos químicos. Dá-se a denominação de caldas nutricionais devido às substâncias orgânicas e minerais que possuem esses produtos e pela diversidade de micronutrientes existentes na formulação, os quais exercem ação benéfica sobre o metabolismo das plantas, aumentando a proteossíntese. Entre eles estão as cinzas, leite ou soro de leite, água de vermicomposto, enxofre, calda bordalesa, calda sulfocálcica e esterco líquido fermentado enriquecido com macro e micronutrientes (MEIRELLES; VENTURIN; GUAZELLI, 2016).

No Brasil, pesquisas relacionadas ao uso de caldas nutricionais, caldas nutritivas, caldas orgânicas ou biofertilizantes ainda são bastante incipientes. Alguns trabalhos foram conduzidos em diferentes culturas e com o uso de distintos subprodutos da agropecuária, que além de atuarem como biofertilizantes também atuam no manejo preventivo de doenças e de pragas. Trabalhos relatam o uso de urina de vaca, manipueira, calda bordalesa, biofertilizantes com diferentes formulações e também produtos biológicos comerciais, como o Microgeo $\AA$, dentre outros, e que apresentaram resultados distintos entre si.

Nesse sentido, Medeiros, Wanderley e Wanderley (2007) avaliaram a produção de mudas de alface com diferentes substratos e com o uso de fertilizante foliar (organomineral comercial Fertamin, testemunha e três tipos de biofertilizantes, onde estes constituíam-se por diferentes compostos, dentre eles vegetais, cinzas, leite, farinhas caldo de cana, esterco e calcário. Os autores observaram que o fertilizante organomineral comercial Fertamin apresentou os melhores resultados para massa seca da parte aérea, massa seca da raiz e número de folhas e, dentre os biofertilizantes, 
aquele à base de esterco de curral fresco, cinzas, leite e caldo de cana apresentou os menores valores para essas mesmas características avaliadas. Chiconato et al. (2013) conduziram um trabalho na cultura da alface onde avaliaram a aplicação de biofertilizante de origem bovina obtido através da biodigestão anaeróbia, em 04 diferentes doses $\left(10 ; 20 ; 40\right.$ e $\left.60 \mathrm{~m}^{3} \mathrm{ha}^{-1}\right)$ e adubação mineral (testemunha) sob dois níveis de irrigação correspondendo a 50\% e 100\% da evapotranspiração e constataram a eficiência do uso do biofertilizante na maior dose $\left(60 \mathrm{~m}^{3} \mathrm{ha}^{-1}\right)$ onde verificaram maiores valores nas variáveis: altura, número de folhas, diâmetro e massa fresca da parte aérea das plantas de alface.

Em trabalho conduzido por Andrade et al. (2014), foram utilizadas diferentes doses de urina de vaca e húmus de minhoca e solo na composição do substrato para produção de alface. Como resultado, verificaram que as mudas de alface responderam positivamente às doses de urina de vaca, e que a dose de 40 $\mathrm{mL}$ se mostrou como mais eficiente, no entanto, o uso de húmus de minhoca como substrato não interferiu nos resultados da cultura. Tošić, Golić e Radosavac (2016), em trabalho realizado com alface produzida em casa de vegetação com o uso de um biofertilizante comercial denominado Bioaktiv® constituído por Bacillus subtilis, Azotobacter sp., Penicillium e Fusarium Spoxalicum, verificaram que com a aplicação deste houve um aumento de $17,7 \%$ no rendimento da cultura da alface. Cardoso, Lopes e Mendes (2017) observaram na cultura da alface com o uso de Microgeo ${ }^{\circledR}$ (150 1 ha-1) que com o uso deste produto biológico o diâmetro do caule, o número de folhas/planta, o comprimento do sistema radicular, a produção de massa de matéria fresca e seca das plantas foram maiores comparativamente à testemunha.

Diante do exposto, objetivando o uso de práticas produtivas sustentáveis e com possibilidade de inserção em propriedades familiares, tem-se como objetivo do presente trabalho avaliar a utilização de diferentes tipos e concentrações de caldas nutricionais em atributos agronômicos da alface. 


\section{MATERIAL E MÉTODOS}

O presente trabalho foi conduzido no período de 28/08/2016 a 28/10/2016 em uma propriedade rural, localizada no interior do município de Ronda Alta (RS), em canteiros cobertos com tela preta com abertura de malha de $50 \%$. O município tem como altitude 450 metros em relação ao nível do mar e está localizado em uma latitude de $27^{\circ} 46^{\prime}$ - Sul e longitude de 52048' - Oeste. O local possui relevo ondulado e os solos são considerados de boa fertilidade. O clima é subtropical com temperatura média de $18^{\circ} \mathrm{C}$ e a precipitação anual é de aproximadamente 2.077 $\mathrm{mm}$, com chuvas distribuídas durante o ano (IBGE, 2017a).

$\mathrm{Na}$ área de instalação do experimento foi realizada análise de solo em dezembro de 2015, com posterior correção nutricional e calagem adequados para a cultura de acordo com a Sociedade Brasileira de Ciência do Solo (2004). Na região de Ronda Alta predomina solos do tipo Latossolo Roxo álico (Latossolos Vermelhos) (IBGE, 2017b), sendo este o mesmo que predomina no local de condução do experimento. De acordo com a análise, foi aplicado $50 \mathrm{~kg}$ de calcário de concha, para a correção da acidez do solo. Como fonte nutricional, foram aplicados $6,5 \mathrm{~kg}$ de NPK na formulação 5-20-20, conforme recomendações da Sociedade Brasileira de Ciência de Solo (2004). Após a correção e adubação do solo foi realizada gradagem para incorporação dos mesmos ao solo.

A preparação dos canteiros ocorreu de forma manual, com auxílio de enxada. Cada canteiro foi preparado com as seguintes dimensões: $10 \mathrm{~cm}$ de altura, $70 \mathrm{~cm}$ de largura e 8,5 metros de comprimento. As mudas de alface da cultivar BS AC0055, do grupo solta crespa, foram adquiridas em agropecuária do município e encontravamse em bandejas de poliestireno expandido, com substrato comercial. Após a aquisição das mesmas, foi realizado o transplantio das mudas a campo, em canteiros com espaçamento de $0,30 \mathrm{~m} \times 0,30 \mathrm{~m}$, entre plantas e fileiras, respectivamente. As mudas transplantadas estavam com quatro folhas.

Os canteiros foram cobertos com tela preta abertura de malha de $50 \%$. A irrigação foi realizada diariamente, com o auxílio de regadores, aplicando-se 10 litros de água por canteiro, o que representou uma lâmina de aplicação de 1,6 mm. Para o manejo de plantas espontâneas, quando necessário, fez-se uso de capina manual 
com auxílio de enxada.

Os tratamentos consistiram no uso de distintos tipos e concentrações de caldas nutricionais: T1: húmus líquido a 5\%; T2: húmus líquido a 2,5\%; T3: calda bordalesa a $0,5 \%$; T4: calda bordalesa a $0,1 \%$; T5: Microgeo ${ }^{\circledR}$ a $0,5 \%$; T6: Microgeo ${ }^{\circledR}$ a 1,0\%; T7: testemunha (com apenas água). O delineamento experimental foi em blocos ao acaso, com sete tratamentos e cinco repetições de oito plantas.

Quanto à elaboração das caldas nutricionais, a calda a base de húmus líquido e a calda bordalesa foram preparadas na própria propriedade. Quanto à calda preparada com Microgeo ${ }^{\circledR}$, a mesma foi adquirida junto a produtores da região. Para o preparo da calda a base de húmus, a mesma foi realizada após a coleta do húmus sólido, no minhocário. Este foi pesado e diluído em água, sendo que foram utilizadas 1.000 gramas em 5 litros de água para a solução a 5\%, e 500 gramas em 5 litros de água para a solução a 2,5\%, conforme recomendações de Schiedeck e Schwengber (2010). Esse processo foi realizado cinco dias antes de cada aplicação, tempo necessário para que a calda estivesse pronta para uso. Para o preparo da calda bordalesa efetuou-se o preparo isoladamente do sulfato de cobre e da cal virgem (200 gramas de sulfato de cobre em 2 litros de água e a mesma medida para a cal virgem), onde foram estabelecidos valores proporcionais aos definidos por Schwengber, Schiedeck e Gonçalves (2007). A aplicação das mesmas foi realizada com a utilização de pulverizador costal, com capacidade para 10 litros. Foi aplicado um volume de três litros de calda para cada tratamento. Para o tratamento testemunha foi utilizado somente água. A primeira aplicação foi realizada uma semana após o transplantio das mudas, quando as plântulas estavam com seis folhas. As demais foram realizadas a cada 15 dias, sendo a última aplicação realizada uma semana antes da colheita, o que totalizou quatro aplicações.

A colheita das alfaces foi realizada aos 60 dias após a implantação do experimento, quando as plantas já apresentavam padrão adequado de desenvolvimento vegetativo e as variáveis avaliadas foram: altura da parte aérea e comprimento do sistema radicular, perímetro da parte aérea, peso da matéria seca da alface e a redução do peso da alface.

A medida do perímetro da parte aérea das alfaces foi realizada com as plantas ainda nos canteiros, com auxílio de fita métrica, na parte mediana da planta. 
Após as alfaces terem sido retiradas do solo, separou-se a parte aérea do seu sistema radicular com auxílio de uma faca. O sistema radicular das plantas foi submetido a um processo de lavagem para retirada do solo presente e assim serem conduzidas às avaliações inerentes a esta pesquisa.

Para a determinação das variáveis procedeu-se da seguinte forma: a altura das plantas e o comprimento do sistema radicular foram medidos com auxílio de uma régua graduada (em todas as plantas do experimento); o perímetro foi medido com auxílio de uma fita métrica (em todas as plantas do experimento); o peso de matéria seca foi obtido após submissão das amostras em estufa de circulação de ar forçada a $70^{\circ} \mathrm{C}$, até atingirem peso constante (em 05 plantas por repetição); para a determinação da redução de peso da alface, simulando o tempo de prateleira das mesmas, foi realizada uma simulação em câmara refrigerada do tipo B. O. D. (Demanda Bioquímica de Oxigênio), simulado com o uso de temperatura de 10 ${ }^{\circ} \mathrm{C}$, por oito dias, com fotoperíodo de 12 horas, nos primeiros três dias, sendo que nos demais o fotoperíodo foi desligado (em 03 plantas por repetição). Não houve controle de umidade relativa. A pesagem das alfaces deu-se aos oito dias de estocagem, com auxílio de balança analítica.

Os dados obtidos foram submetidos à análise de variância e, quando significativos, as médias foram comparadas entre si pelo teste de Tukey a 5\% de probabilidade, por meio do programa estatístico Winstat 2.0. Os dados referentes à variável redução de peso da alface foram transformados por meio da equação arc sen da raiz quadrada de $\mathrm{x} / 100$.

\section{RESULTADOS E DISCUSSÃO}

Os resultados demonstram diferença significativa para as variáveis altura de planta (AP), comprimento da raiz (CR), matéria seca do sistema radicular (MSSR) e redução de peso (RP) (Tabela 1). Já para as variáveis perímetro de plantas (PP) e matéria seca da parte aérea (MSPA), não houve diferença significativa.

Para a variável AP, observou-se que o tratamento T3 (calda bordalesa a 0,5\%) foi superior ao tratamento T5 (Microgeo ${ }^{\circledR}$ a $0,5 \%$ ) em 14,8\%. Contudo, os demais tratamentos não diferiram entre si (Tabela 1). O principal constituinte da calda 
bordalesa é o cobre, micronutriente que pode ser disponibilizado para as plantas na forma de sulfato de cobre (CuSo4) (CLEMENTE, 2015). Embora o cobre seja um micronutriente requerido pelas plantas em baixas concentrações $\left(\leq 400 \mathrm{mg} \mathrm{Kg}^{-1}\right.$ MS), no entanto, este desempenha função importante no transporte de elétrons (MARENCO; LOPES, 2009). Uma forma de fornecimento de micronutrientes às plantas é por meio da adubação foliar. Como os micronutrientes são exigidos pela planta em pequenas quantidades, esta forma de aplicação evita perdas, condição comum quando utilizada adubação via solo (CLEMENTE, 2015).

Tabela 1. Valores médios de altura, perímetro, massa seca da parte aérea (MSPA), comprimento de raiz (CR), massa seca do sistema radicular (MSSR) e redução de peso em B. O. D. de alfaces produzidas com distintos tipos e concentrações de caldas nutricionais

\begin{tabular}{l|c|c|c|c|c|c}
\hline Tratamento & Altura (cm) & Perímetro (cm) & MSPA (g) & CR (cm) & MSSR (g) & $\begin{array}{c}\text { Redução de } \\
\text { peso }(\mathrm{g})\end{array}$ \\
\hline T1* & $19,85 \mathrm{ab} *$ & $54,84 \mathrm{~ns}$ & $4,23 \mathrm{~ns}$ & $14,46 \mathrm{a}$ & $0,79 \mathrm{a}$ & $21,02 \mathrm{c}$ \\
T2 & $19,88 \mathrm{ab}$ & 56,87 & 5,10 & $13,92 \mathrm{ab}$ & $0,66 \mathrm{ab}$ & $35,59 \mathrm{bc}$ \\
T3 & $20,81 \mathrm{a}$ & 54,02 & 4,43 & $10,85 \mathrm{~d}$ & $0,27 \mathrm{c}$ & $44,86 \mathrm{abc}$ \\
T4 & $20,43 \mathrm{ab}$ & 58,09 & 4,20 & $11,49 \mathrm{~cd}$ & $0,24 \mathrm{c}$ & $53,37 \mathrm{ab}$ \\
T5 & $18,13 \mathrm{~b}$ & 56,35 & 4,07 & $11,45 \mathrm{~cd}$ & $0,76 \mathrm{ab}$ & $58,86 \mathrm{ab}$ \\
T6 & $18,94 \mathrm{ab}$ & 52,72 & 3,95 & $10,92 \mathrm{~d}$ & $0,70 \mathrm{ab}$ & $51,97 \mathrm{ab}$ \\
T7 & $19,37 \mathrm{ab}$ & 57,62 & 4,08 & $12,72 \mathrm{bc}$ & $0,46 \mathrm{bc}$ & $62,64 \mathrm{a}$ \\
Média & 19,63 & 55,78 & 4,29 & 12,25 & 0,55 & 46,90 \\
CV (\%) & 7 & 8,5 & 18 & 7 & 28 & 21 \\
DMS & 2,63 & 9,66 & 1,51 & 1,46 & 0,32 & 25,66 \\
\hline
\end{tabular}

ns $=$ não significativo.

* T1: Húmus líquido a 5\%; T2: Húmus líquido a 2,5\%; T3: Calda bordalesa a 0,5\%; T4: Calda bordalesa a $0,1 \%$; T5: Microgeo a 0,5\%; T6: Microgeo a 1,0\%; T7: Testemunha.

** Médias seguidas pela mesma letra na coluna não diferem significativamente pelo Teste de Tukey a $5 \%$ de probabilidade de erro.

Em trabalho conduzido por Baptista e Resende (2012) na cultura do tomateiro conduzido em casa de vegetação verificaram que a produção total foi significativamente maior nas plantas tratadas com calda bordalesa em relação ao uso de óleo de neen e de alho e aquela também foi mais eficiente no controle das doenças foliares no tomateiro em sistema orgânico, tanto nos experimentos 
em casa de vegetação quanto no campo. No entanto, percebe-se a preocupação de pesquisadores quanto ao uso do cobre, uma vez que este tem sido utilizado massivamente na agricultura. De acordo com a Portaria $n^{0}$ 685, de 27 de agosto de 1998, da Agência Nacional de Vigilância Sanitária (ANVISA) (BRASIL, 1998), que regulamenta os limites máximos de tolerância para contaminantes inorgânicos em alimentos, para frutas, hortaliças e sementes oleaginosas in natura e industrializadas o limite máximo de tolerância para o cobre é de $10 \mathrm{mg} / \mathrm{kg}$. Esta condição denota grande preocupação por parte dos agricultores que têm no uso deste produto um grande aliado em seus sistemas de produção, mas que aos poucos tenderá a ser substituído por outras formas menos prejudiciais. Nesse sentido, o uso de biofertilizantes poderá ser uma alternativa de uso conforme constata-se no trabalho de Chiconato et al. (2013), onde maior altura das alfaces foi obtida com a utilização de biofertilizante de origem bovina gerado através da biodigestão anaeróbia na dose de $60 \mathrm{~m}^{3} \mathrm{ha}^{-1}$.

Em relação à variável $\mathrm{CR}$ o tratamento $\mathrm{T} 1$ (húmus líquido a 5\%) não diferiu do tratamento T2 (húmus líquido a 2,5\%), sendo T1 superior aos demais tratamentos avaliados (Tabela 01). Os menores comprimentos de raiz foram observados nos tratamentos T3 e T6, os quais não diferiram do T4 e T5, mas foram inferiores aos valores observados na testemunha (Tabela 01). Segundo Anjos, Aquino e Schiedeck (2015), o húmus, em sua constituição na forma sólida, também conhecido como vermicomposto ou lumbricomposto, apresenta boas características físicas, bom conteúdo de matéria orgânica, nutrientes e fitorreguladores. Os autores ainda destacam que o húmus possibilita o equilíbrio nos aspectos físicos, químicos e biológicos do solo, dessa forma age de forma positiva no desenvolvimento e produtividade das culturas. Em relação ao húmus líquido, este é produzido a partir da mistura do húmus de minhoca com água e tem apresentado bons resultados em relação à sua utilização como fonte de nutriente e indutor de resistência nas plantas (GONÇALVES; SCHIEDECK; SCHWENGBER, 2009). Ainda, de acordo com Schiedeck e Schwengber (2010), o húmus líquido possui em sua composição inúmeros nutrientes além de ácidos orgânicos, capazes de estimular o crescimento das plantas, bem como microorganismos que auxiliam no equilíbrio biológico do solo. Conforme esses autores, o uso do húmus líquido, na cultura do morangueiro, 
na concentração de $10 \%$ e na dose de $1 \mathrm{~L} \mathrm{~m}^{-2}$ a cada 15 dias, demonstrou resultados satisfatórios, em complemento à adubação orgânica de base com 20 a 30 t ha' ${ }^{-1}$.

Para a variável MSSR, o tratamento T1 (húmus líquido a 5 \%) apresentou maior valor, o qual diferiu dos tratamentos T3 (calda bordalesa a 0,5\%), T4 (calda bordalesa a 0,1\%) e T7 (testemunha), sendo a média destes 55,55\% inferior à média dos tratamentos T1, T2, T5 e T6 os quais não diferiram entre si (Tabela 01). Conforme os resultados obtidos, pode-se destacar a relevância do uso do húmus líquido aliado ao Microgeo ${ }^{\circledR}$. Medeiros, Wanderley e Wanderley (2007), embora tenham observado melhor resultado para a massa seca da raiz com o uso de fertilizante foliar (organomineral comercial) em trabalho conduzido com mudas de alface, citam também o bom desempenho alcançado pelas plantas submetidas aos tratamentos de origem orgânica ou seja, com o uso de biofertilizantes. De acordo com Gonçalves, Schiedeck e Schwengber (2009), os biofertilizantes são fertiprotetores, provenientes de um processo de decomposição da matéria orgânica (animal ou vegetal). Conforme Medeiros et al. (2003) os biofertilizantes funcionam como promotores de crescimento (equilíbrio nutricional) e como elicitores na indução de resistência sistêmica na planta. Ainda, conforme Medeiros, Wanderley e Wanderley (2007), tais produtos podem ser elaborados pelo próprio agricultor, uma vez que geralmente são compostos de excrementos de animais obtidos na própria propriedade, assim geram economia de insumos importados além do que promovem melhorias no saneamento ambiental.

O uso do Microgeo ${ }^{\circledR}$ foi destacado no trabalho conduzido por Cardoso, Lopes e Mendes (2017), onde observaram maior produção de massa seca de plantas de alface comparativamente à testemunha. O Microgeo ${ }^{\circledR}$ é um composto orgânico, certificado pelo Instituto Biodinâmico (IBD), preparado com várias fontes orgânicas e inorgânicas. É enriquecido com rochas moídas (silicatos de magnésio, cálcio, ferro) e outros oligoelementos fundamentais para estimular o metabolismo primário e secundário das plantas (MEDEIROS et al., 2003). Dessa forma, por ser um produto certificado, seu uso não tem restrições para o uso nos sistemas de produção orgânicos. Tal condição torna-se extremamente relevante uma vez que neste sistema de produção há limitação de disponibilidade no mercado de produtos certificados.

Quanto à variável RP, a maior redução foi observada no tratamento T7 
(testemunha), com 62,64 g ao longo do período de avaliação, o qual diferiu apenas do T1 e T2, igualando-se aos demais. O tratamento T1 (húmus líquido a 5\%) foi o que apresentou menor redução de peso no período (21,02 g), igualando-se aos tratamentos T2 (húmus líquido a 2,5\%) e T3 (calda bordalesa a 0,5\%), sendo, nestas condições, os tratamentos que apresentaram os resultados mais satisfatórios (Tabela 01). A redução de peso da alface pode ser considerada como um atributo relacionado à sua vida útil ou tempo-de-prateleira. A vida útil de um alimento ou tempo-de-prateleira é estimado através do tempo, em determinada condição de estocagem, que o produto leva para atingir uma condição inaceitável ou então imprópria para consumo (PINTO, 2015). Do ponto de vista de vida-de-prateleira, a qualidade dos alimentos perpassa por aspectos fisiológicos, valores nutricionais e atributos sensoriais como cor, sabor e textura ou consistência. A diminuição da qualidade e a redução de vida-de-prateleira podem ser consequência do efeito de uma ou mais destas propriedades (PFEIFFER et al., 1999). Nesse sentido, é possível perceber a ação positiva do uso do húmus líquido (2,5\% e 5\%) e da calda bordalesa $(0,5 \%)$ na pós-colheita da alface, pois estes agem também na manutenção do peso do vegetal, o qual é um aspecto positivo, pois assim é possível conservar o produto adequadamente. Em trabalho conduzido por Menezes Júnior, Gonçalves e Vieira Neto (2013), no cultivo da cebola cultivar Epagri 352 Bola Precoce, verificaram que o uso de biofertilizantes não aumentou as perdas em pós-colheita, no entanto, no sistema orgânico (adubação orgânica com o uso parcelado de biofertilizantes) houve a redução em $43 \%$ da produtividade em relação ao cultivo convencional. Ferreira (2014), em avaliação no cultivo de tomateiro variedade Perinha Água Branca, com a utilização de calda viçosa 1\%; calda bordalesa a 1\%; calda sulfocálcica em emulsão a $1,5 \%$; extrato de alho $8 \%$ e testemunha, não observou diferenças significativas entre os tratamentos sobre o número e massa fresca de frutos. Conforme Reis et al. (2014), a perda de água em alfaces aumenta com o período de armazenamento. Em seu trabalho, os autores verificaram que alfaces do tipo crespa, cultivar Isabela, embaladas totalmente fechadas apresentam menor perda de água que alfaces embaladas totalmente abertas. E, ainda, aos 15 dias de armazenamento, alfaces submetidas à condição de temperatura de $5^{\circ} \mathrm{C}$, umidade relativa de $90 \% \pm \mathrm{SD}$ e na ausência de luz, parcialmente fechadas ou totalmente fechadas, apresentavam 
maior perda de água quando cultivadas em sistema de cultivo convencional, comparativamente ao sistema de cultivo orgânico. De acordo com Howard (2012), o cultivo de hortaliças por meio da utilização de adubos sintéticos poderá resultar em uma produtividade satisfatória, no entanto, o sabor, a qualidade e a capacidade de conservação do produto são marcadamente inferiores àquele produto cultivado com o uso de estercos. O autor complementa que hortaliças produzidas com a utilização de húmus são tenras, quebradiças e apresentam bastante sabor.

De modo geral, é importante ressaltar, de acordo com os resultados obtidos neste trabalho, que o húmus líquido se apresenta como uma opção para uso no cultivo de alface, principalmente nos sistemas de produção orgânica, pois são de fácil elaboração e pouca mão de obra e apresentam baixo custo de obtenção, a fim de proporcionar resultados satisfatórios.

\section{CONCLUSÃO}

Indica-se o uso de caldas nutricionais para o cultivo de alface (Lactuca sativa). Sobre os atributos agronômicos, o uso de húmus líquido (2,5\% e 5\%) promove maior comprimento de raízes e menor redução do peso da alface.

\section{REFERÊNCIAS}

ANDRADE, A. de F. et al. Uso de urina de vaca e húmus de minhoca no crescimento de alface. Revista Terceiro Incluído, v. 4, n. 2, p. 186-196, jul./dez. 2014.

ANJOS, J. L. dos; AQUINO, A. M. de; SCHIEDECK, G. Minhocultura e vermicompostagem: interface com sistema de produção, meio ambiente e agricultura de base familiar. Brasília: Embrapa, 2015. 231 p.

BAPTISTA, M. J.; RESENDE, F. V. Uso de calda bordalesa, extratos vegetais e biofertilizante para controle de doenças foliares do tomateiro em sistema orgânico de produção. Brasília: Embrapa Hortaliças, 2012. 22 p. (Boletim de pesquisa e desenvolvimento Embrapa Hortaliças, n. 82).

BRASIL. Ministério da Saúde. Portaria nº 685, de 27 de agosto de 1998. Aprova o 
Regulamento Técnico: Princípios Gerais para o Estabelecimento de Níveis Máximos de Contaminantes Químicos em Alimentos e seu Anexo: Limites máximos de tolerância para contaminantes inorgânicos. Diário Oficial da União, seção 1, Brasília, DF, n. 183, p. 3, 28 ago. 1998.

CARDOSO, S. S.; LOPES, M. C.; MENDES, G. M. S. Desenvolvimento de alface submetida à adubação com Microgeo ${ }^{\circledR}$. Revista Mirante, v. 10, n. 2, p. 43-53, jul. 2017.

CHICONATO, D. A. et al. Resposta da alface à aplicação de biofertilizante sob dois níveis de irrigação. Bioscience Journal, v. 29, n. 2, p. 392-399, mar./abr. 2013.

CLEMENTE, F. M. V. T. Produção de hortaliças para agricultura familiar. Brasília: Embrapa, 2015. 108 p.

FERREIRA, F. V. Caldas alternativas no controle de mancha-de-estenfilio (Stemphylium solani) em tomateiro sob manejo orgânico na Baixada Fluminense, RJ. 2014. 40 f. Dissertação (Mestrado em Ciências) - Universidade Federal Rural do Rio de Janeiro, Rio de Janeiro, 2014.

FILGUEIRA, F. A. R. Novo manual de olericultura: agrotecnologia moderna na produção e comercialização de hortaliças. Viçosa: Ed. UFV, 2012. 421 p.

GONÇALVES, M. de M.; SCHIEDECK, G.; SCHWENGBER, J. E. Produção e uso de biofertilizantes em sistemas de produção de base ecológica. Pelotas: Embrapa Clima Temperado, 2009. 7 p. (Circular Técnica, n. 78).

HOWARD, S. A. Um testamento agrícola. São Paulo: Expressão Popular, 2012. 360 p.

IBGE. Mapa exploratório de solos do Estado do Rio Grande do Sul. 2017a.

Disponível em: http://geoftp.ibge.gov.br/informacoes_ambientais/pedologia/mapas/ unidades_da_federacao/rs_pedologia.pdf. Acesso em: 15 ago. 2017.

IBGE. Ronda Alta: Rio Grande do Sul. 2017b. Disponível em: http://biblioteca.ibge. gov.br/visualizacao/dtbs/riograndedosul/rondaalta.pdf. Acesso em: 4 maio 2017. 
MARENCO, R. A.; LOPES, N. F. Fisiologia vegetal: fotossíntese, respiração, relações hídricas e nutrição mineral. Viçosa: Editora UFV, 2009. 486 p.

MEDEIROS, M. B. de; WANDERLEY, P. A.; WANDERLEY, M. J. A. Biofertilizantes líquidos: processo trofobiótico para proteção de plantas em cultivos orgânicos. Revista Biotecnologia Ciência e Desenvolvimento, v. 31, p. 38-44, jul./dez. 2003.

MEDEIROS, D. C. et al. Produção de mudas de alface com biofertilizantes e substratos. Horticultura Brasileira, v. 25, n. 3, p. 433-436, jul./set. 2007.

MEIRELLES, L.; VENTURIN, L.; GUAZELLI, M. J. Agricultura ecológica: alguns princípios básicos. Ipê: Centro Ecológico, 2016. 74 p.

MENEZES JÚNIOR, F. O. G. de; GONÇALVES, P. A. de S.; VIEIRA NETO, J. Produtividade, incidência de tripes e perdas pós-colheita da cebola sob adubação orgânica e uso de biofertilizantes. Revista de Ciências Agroveterinárias, v. 12, n. 3, p. 264$270,2013$.

PFEIFFER, C. et al. Optimizing food packaging and shelf life. Food Technology, v. 53, n. 6, p. 52-59, 1999.

PINTO, J. V. Elaboração de manual prático para determinação de vida-de-prateleira de produtos alimentícios. 2015. 66 f. Trabalho de Conclusão de Curso (Graduação em Engenharia de Alimentos) - Universidade Federal do Rio Grande do Sul, Porto Alegre, 2015.

REIS, H. F. dos et al. Conservação pós-colheita de alface crespa, de cultivo orgânico e convencional, sob atmosfera modificada. Horticultura Brasileira, v. 32, n. 3, p. 303-309, jul./set. 2014.

SCHWENGBER, J. E.; SCHIEDECK, G.; GONÇALVES, M. de M. Preparo e utilização de caldas nutricionais e protetoras de plantas. Pelotas: Embrapa Clima Temperado, 2007. 64 p.

SCHIEDECK, G.; SCHWENGBER, J. E. Húmus líquido: adubação orgânica líquida visando a transição agroecológica. Pelotas: Embrapa Clima Temperado, 2010. 2 p. 
SOCIEDADE BRASILEIRA DE CIÊNCIA DO SOLO. Comissão de Química e Fertilidade do Solo. Manual de adubação e de calagem para os Estados do Rio Grande do Sul e Santa Catarina. Porto Alegre: Sociedade Brasileira de Ciência do Solo/ Núcleo Regional Sul, 2004. 400 p.

TOŠIĆ, I.; GOLIĆ, Z;; RADOSAVAC, A. Effects of the application of biofertilizers on the microflora and yield of lettuce (Lactuca sativa L.). Acta Agriculturae Serbica, v. 21, n. 42 , p. 91-98, 2016.

Recebido em: 15/09/2017

Aceito em: 07/02/2019 